\title{
Leukocyte stability in hemogram samples waiting at room temperature
}

\section{Berrin Oztas}

Department of Biochemistry, Kocaeli University, Faculty of Medicine, Kocaeli, Turkey

\begin{abstract}
Objectives: Management of preanalytical, analytical and post-analytic processes is essential to obtain reliable results in clinical biochemistry laboratories. One of the most significant of these processes is ensuring sample stability. In this study, we aimed to evaluate hourly changes of leukocyte parameters at room temperature for 24 hours.

Methods: In this study, 30 randomly selected hemogram samples from Kocaeli University Faculty of Medicine Central Laboratory were included. These samples were analyzed on the Beckman Coulter Unicel DXH 800 analyzer (Beckman Coulter, Miami, FL) immediately after being admitted to the laboratory (0. hour) and after waiting for $2,4,8,24$ hours in the room $\left(23-25^{\circ} \mathrm{C}\right)$, the results were repeated again. In this study, leukocyte, lymphocyte, basophil, neutrophil, monocyte, eosinophil parameters were evaluated using the GraphPad Prism 6 program. The values were expressed as mean \pm Standard deviation (SD). $P<0.05$ was used for statistical significance.

Results: A statistically significant difference was observed in the levels of leukocyte, lymphocyte, basophil, neutrophil and monocyte parameters. No significant difference was observed in eosinophil levels. The findings showed that the earliest increase occurred in neutrophil and lymphocyte values at the $2^{\text {nd }}$ hour $(p<0.001)$. An increase in the $4^{\text {th }}$-hour measurements was observed in basophil and monocyte levels $(p<0.001)$.

Conclusion: Our study showed that leukocyte subparameters, neutrophils and lymphocytes were the earliest affected parameters. Our findings suggest that when the waiting times of hemogram samples exceed two hours, the results will not be reliable concerning leukocyte parameters.
\end{abstract}

Keywords: Leukocyte, hemogram, preanalytical stage

L aboratory testing process is divided into preanalytical, analytical and post-analytic stages. The vast majority of laboratory errors (up to 70\%) emerge from the pre-analytical phase [1]. This phase is influenced by many variables, including the preparation of the patient before testing, the procedures used to collect and transport the biological specimens, as well as the time and storage conditions of blood samples before analysis. In particular, it was recently proven that the stability of many hematological parameters is strongly influenced by the storage temperature of the sample and the time elapsed between collection and analysis [2-4]. To give accurate and reliable results, the sample must be delivered to the laboratory at a certain temperature and time. In this study, we aimed to evaluate hourly changes of leukocyte parameters at room temperature for 24 hours.

\section{Materials and Methods}

In the study, 30 randomly selected hemogram samples (K3 -EDTA (tripotassium ethylenediamine-tetraacetate) anticoagulated blood specimens) from Kocaeli University Faculty of Medicine Central Laboratory were included. These samples were analyzed on the Beckman Coulter Unicel DXH 800 analyzer (Beckman Coulter, Miami, FL) immediately after being admitted to the laboratory ( 0 . hour) and It was repeated after waiting in room temperature $\left(23-25^{\circ} \mathrm{C}\right)$ for $2,4,8,24$ hours. In

Address for correspondence: Berrin Oztas, MD. Department of Biochemistry, Kocaeli University, Faculty of Medicine, Kocaeli, Turkey

Phone: +90 5052365198 E-mail: berrinoztas@gmail.com ORCID: 0000-0002-2907-5108

Submitted Date: August 08, 2020 Accepted Date: August 16, 2020 Available Online Date: October 06, 2020

${ }^{\circ}$ Copyright 2020 by International Journal of Medical Biochemistry - Available online at www.internationalbiochemistry.com

OPEN ACCESS This work is licensed under a Creative Commons Attribution-NonCommercial 4.0 International License. 
this study, leukocyte, lymphocyte, basophil, neutrophil, monocyte, eosinophil parameters were evaluated with the GraphPad Prism 6 program. The conformity of the data to normal distribution was performed using the Kolmogorov-Smirnov test. While leukocyte, lymphocyte and neutrophil parameters show normal distribution, basophil, monocyte, eosinophil parameters do not fit the normal distribution. ANOVA was used for the analysis of parameters that fit normally. Friedman test was used in the analysis of others. The values were expressed as mean \pm Standard deviation (SD). P-values of $<0.05$ were considered statistically significant.

\section{Results}

A statistically significant difference was observed in the levels of leukocyte, lymphocyte, basophil, neutrophil and monocyte parameters $(p<0.001)$. No significant difference was observed in eosinophil levels. The findings showed that the earliest increase occurred in neutrophil and lymphocyte values at the $2^{\text {nd }}$ hour $(p<0.001)$. An increase in the $4^{\text {th }}$-hour measurements was observed in basophil and monocyte levels $(p<0.001)$ (Table 1$)$.

\section{Discussion}

One of the most significant preanalytical stage processes is ensuring sample stability.

To give accurate and reliable results, the sample must be delivered to the laboratory at a certain temperature and time [5]. In this study, we aimed to evaluate hourly changes of leukocyte parameters at room temperature for 24 hours.

In our study, a statistically significant difference in room temperature was observed in the levels of leukocyte, lymphocyte, basophil, neutrophil, monocyte parameters. No significant difference was observed in eosinophil levels. The findings showed that the earliest increase occurred in neutrophil and lymphocyte values at the $2^{\text {nd }}$ hour $(p<0.001)$. An increase in the $4^{\text {th }}$-hour measurements was observed in basophil and monocyte levels $(p<0.001)$.

Buoro et al. examined 10 normal 40 abnormal blood samples at $2,4,6,8,24,36$ and 48 hours at room temperature and $4^{\circ} \mathrm{C}$. They found the abnormal blood samples to be stable up to eight hours both at room temperature and at $4^{\circ} \mathrm{C}$. However, considering other parameters, they found that up to two hours of hemogram samples did not show any significant analytical changes in storage [6]. The analyzers in this study, Mindray BC me 6800 and Sysmex XN - 9000 were used for fluorescent and light scattering. Both BC-6800 and XN-9000 apply flow cytometric methods, although different reagents for red blood cell lysis and white blood cell differentials are used. Beckman Coulter UniCel DxH 800 analyzer, in our study, is a fully automated hematology analyzer, which identifies cells using the Coulter technique based on the principle of impedance technology and light scatter analysis [7]. Ciepiela et al. showed that the results of the white blood cell counts poor agreement between the three studied analyzers [8].

Gulati et al. also investigated the stability of 40 K3 EDTA blood samples for one week at room temperature. They found an increase in neutrophil, lymphocyte and eosinophil counts. However, they did not observe the same increase in monocyte numbers. They concluded that these changes in the leukocyte sub-parameters could be due to cellular degeneration known as loss of individual cell properties and cell aging [9]. In our study, it supports Gulati et al.'s findings.

\section{Conclusion}

Our study showed that leukocyte subparameters, neutrophils and lymphocytes were the earliest affected parameters. Our findings suggest that when the waiting times of hemogram samples exceed two hours, the results will not be reliable concerning leukocyte subparameters.

Conflict of Interest: No conflict of interest is declared by the authors.

Financial Disclosure: This research did not receive any specific grant from funding agencies in the public, commercial, or not-forprofit sectors.

Peer-review: Externally peer-reviewed.

Table 1. Changes of the leukocyte, basophil, eosinophil, neutrophil, monocyte and lymphocyte parameters at room temperature

\begin{tabular}{|c|c|c|c|c|c|}
\hline & $\begin{array}{l}\text { 0. hour } \\
\text { mean } \pm S D\end{array}$ & $\begin{array}{l}\text { 2. hour } \\
\text { mean } \pm S D\end{array}$ & $\begin{array}{l}\text { 4. hour } \\
\text { mean } \pm S D\end{array}$ & $\begin{array}{l}\text { 8. hour } \\
\text { mean } \pm S D\end{array}$ & $\begin{array}{l}\text { 24. hour } \\
\text { mean } \pm S D\end{array}$ \\
\hline Leukocyte $\left(10^{3} / \mu \mathrm{L}\right)$ & $6.770 \pm 1.94$ & $7.12 \pm 2.04^{*}$ & $7.13 \pm 2.05^{*}$ & $7.18 \pm 2.03^{*}$ & $7.12 \pm 1.98^{*}$ \\
\hline Basophil $\left(10^{3} / \mu \mathrm{L}\right)$ & $0.046 \pm 0.023$ & $0.052 \pm 0.027$ & $0.062 \pm 0.036^{*}$ & $0.083 \pm 0.066^{*}$ & $0.085 \pm 0.047^{*}$ \\
\hline Eosinophil $\left(10^{3} / \mu \mathrm{L}\right)$ & $0.16 \pm 0.12$ & $0.17 \pm 0.12$ & $0.17 \pm 0.12$ & $0.17 \pm 0.13$ & $0.17 \pm 0.12$ \\
\hline Neutrophil $\left(10^{3} / \mu \mathrm{L}\right)$ & $3.63 \pm 1.13$ & $3.79 \pm 1.17^{*}$ & $3.79 \pm 1.19^{*}$ & $3.77 \pm 1.16^{*}$ & $3.82 \pm 1.18^{*}$ \\
\hline Monocyte $\left(10^{3} / \mu \mathrm{L}\right)$ & $0.61 \pm 0.25$ & $0.64 \pm 0.27$ & $0.66 \pm 0.27^{*}$ & $0.66 \pm 0.29 *$ & $0.58 \pm 0.25$ \\
\hline Lymphocyte $\left(10^{3} / \mu \mathrm{L}\right)$ & $2.33 \pm 0.77$ & $2.48 \pm 0.83^{*}$ & $2.46 \pm 0.83^{*}$ & $2.50 \pm 0.83^{*}$ & $2.41 \pm 0.80^{*}$ \\
\hline
\end{tabular}

${ }^{*} p<0.001$ 


\section{References}

1. Lippi G, Guidi GC, Mattiuzzi C, Plebani M. Preanalytical variability: the dark side of the moon in laboratory testing. Clin Chem Lab Med 2006;44(4):358-65. [CrossRef]

2. Imeri F, Herklotz R, Risch L, Arbetsleitner C, Zerlauth M, Risch GM, et al. Stability of hematological analytes depends on the hematology analyser used: a stability study with Bayer Advia 120, Beckman Coulter LH 750 and Sysmex XE 2100. Clin Chim Acta 2008;397(1-2):68-71. [CrossRef]

3. Zini G; International Council for Standardization in Haematology (ICSH). Stability of complete blood count parameters with storage: toward defined specifications for different diagnostic applications. Int J Lab Hematol 2014;36:111-3. [CrossRef]

4. Briggs C, Culp N, Davis B, d'Onofrio G, Zini G, Machin SJ, et al; International Council for Standardization of Haematology. ICSH guidelines for the evaluation of blood cell analysers including those used for differential leucocyte and reticulocyte counting. Int J Lab Hematol 2014;36(2):613-27. [CrossRef]

5. Ikeda K, Ichihara K, Hashiguchi T, Hidaka Y, Kang D, Maekawa $\mathrm{M}$, et al; Committee for Standardization, The Japanese Society of Laboratory Medicine (JSLM). Evaluation of the short-term stability of specimens for clinical laboratory testing. Biopreserv Biobank 2015;13(2):135-43. [CrossRef]

6. Buoro S, Mecca T, Seghezzi M, Manenti B, Cerutti L, Dominoni $\mathrm{P}$, et al. Assessment of blood sample stability for complete blood count using the Sysmex XN-9000 and Mindray BC6800 analyzers. Rev Bras Hematol Hemoter 2016;38(3):22539. [CrossRef]

7. Beckman Coulter Inc. UniCel DxH 800 Coulter cellular analysis system, instructions for use: PN B26647AE. Brea, USA: Beckman Coulter Inc; 2017. p. 127.

8. Ciepiela O, Kotuła I, Kierat S, Sieczkowska S, Podsiadłowska A, Jenczelewska A, et al. A Comparison of Mindray BC-6800, Sysmex XN-2000, and Beckman Coulter LH750 Automated Hematology Analyzers: A Pediatric Study. J Clin Lab Anal 2016;30(6):1128-34. [CrossRef]

9. Gulati GL, Hyland LJ, Kocher W, Schwarting R. Changes in automated complete blood cell count and differential leukocyte count results induced by storage of blood at room temperature. Arch Pathol Lab Med 2002;126(3):336-42. 